University of Nebraska - Lincoln

DigitalCommons@University of Nebraska - Lincoln

1988

\title{
Technological Change and Child Behavior among the !Kung
}

\author{
Patricia Draper \\ University of Nebraska - Lincoln, pdraper1@unl.edu \\ Elizabeth Cashdan \\ University of Pittsburgh
}

Follow this and additional works at: https://digitalcommons.unl.edu/anthropologyfacpub

Part of the Anthropology Commons

Draper, Patricia and Cashdan, Elizabeth, "Technological Change and Child Behavior among the !Kung" (1988). Anthropology Faculty Publications. 37.

https://digitalcommons.unl.edu/anthropologyfacpub/37

This Article is brought to you for free and open access by the Anthropology, Department of at DigitalCommons@University of Nebraska - Lincoln. It has been accepted for inclusion in Anthropology Faculty Publications by an authorized administrator of DigitalCommons@University of Nebraska - Lincoln. 


\section{TECHNOLOGICAL CHANGE AND}

Patricia Draper

Pennsylvania State University

Elizabeth Cashdan

University of Pittsburgh

How does change in one part of a social system affect other parts? This is the central question that must be answered in order to understand the process through which culture changes. This paper is about a small piece of the problem. It investigates how changes in subsistence economy affect child behavior and the relations between parents and children among !Kung Bushmen of Western Botswana. ${ }^{1}$ We will show that the adoption of a sedentary life style and a new technology of food production is associated with changes in the social interactions between parents and children and between children and their peers. The social and physical settings of everyday life also change with economic practices. We will describe these differences and discuss their implications.

Among the !Kung, foraging and settled groups differ markedly in child behavior and in social interactions between parents and children. Compared with bush-living children, sedentary children do more work, range farther from home, show more sex differentiated behaviors, and interact more with peers. These changes are especially interesting since they appear to result from changes in economy and adult work roles, not from a conscious change in child socialization by adults. These findings shed light on the ways in which social and economic changes affect individual behavior and lead to new normative patterns.

\section{ENVIRONMENT AND SOCIALIZATION}

There is a growing literature that describes how social and physical settings influence the social behavior of children. This literature focuses on the ecological contexts in which children are reared and the ways in which features of the environment influence children. Parents have a major influence on children's lives, yet both parents and children are embedded in socio-economic structures that themselves shape the nature of parent-child relationships (Whiting and Whiting 1975; Wohlwill and van Vliet 1985; Whiting 1980). 


\section{Peer Rearing}

The linkage between social organization and children's learning environments is explored in studies of peer rearing and children's task behavior. Peer rearing refers to a type of child rearing, common in technologically simpler societies, in which younger children are cared for by older children, usually but not necessarily siblings (Weisner and Gallimore 1977). This system of child rearing is inconsistent with Western child socialization values, which assume that the parent-child tie is primary and that parents have the major influence on the development of children. Parental influence in child cognitive and social development is, to say the least, well documented both in its positive and negative outcomes for Western societies. It is sometimes not widely appreciated, however, that the intensity of this dyadic relationship speaks more for a particular set of historical, demographic, and economic processes (Aries 1973; Stone 1977; Scheper Hughes 1985) than for any innate or inevitable characteristic of the relationship between parents and their offspring. Anthropological research shows that parent-child relationships take various forms. The intense, oneon-one relationship between children and their biological parents is seen in post-industrial, Westernized society as well as in some technologically simple societies. Peer rearing, on the other hand, is common in middle range societies, where production is primarily domestic and people rely on ties of kinship for most social and political resources.

Attention has focused on the social conditions that encourage peer caretaking, and on its consequences for children (Weisner and Gallimore 1977; Weisner 1987; Munroe and Munroe 1984; Draper and Harpending 1987). Several conditions seem to encourage peer caretaking. These include an agrarian basis of subsistence, domestic groups of suitable size and composition for providing recruits, and a heavy horticultural work load for women, which causes them to press children into service. Peer caretaking is especially likely where women have tasks that take them out of the homestead, for example to distant gardens. In such societies women are not the principal caretakers or companions of young children (Weisner and Gallimore 1977:170). By the age of six to eight months, children are cared for by older children for half or more of each day (Leiderman and Leiderman 1974, 1977; Borgerhoff Mulder and Milton 1985; Ochs 1982).

Various consequences have been recognized for children who act as caretakers. Since girls are preferentially assigned as nurses of younger children, this chore has been identified as a socialization factor that contributes to sex differences in behavior favoring greater nurturance, prosocial behavior, and restricted spatial range on the part of girls (Edwards and Whiting 1980; Ember 1973; Smith 1980; Munroe et al. 1984).

Descriptions of peer rearing usually compare peasant and third world child-rearing practices with the historically recent, parent-centered child rearing of the West. In this analysis we move "back" still farther on the continuum of techno-social complexity to examine a system of parent rearing among a hunting and gathering people. We will show how parent-child relations in this society are transformed in the direction of peer rearing when the hunter gatherers adopt a sedentary, food processing economy. 


\section{Task Assignment}

Studies of children's work have sought to determine the conditions under which children are expected to perform economically useful work at early ages. Children are assigned chores and taught responsibility and obedience where production is centered on the household, women's involvement in subsistence is high and time-consuming, and women's work roles take them out of the home for several hours during the day. These characteristics typify many middle-range, tribal-level peoples, and peasant producers. In such societies, children are likely to work hardest where the ratio of consumers to workers is high (Munroe et al. 1984). Under these conditions, children are socialized to be responsible and obedient, whereas these values are emphasized less among foragers, simple horticulturalists, and industrialized societies (Berry 1967; Munroe and Munroe 1980; Barry, Child, and Bacon 1959; B. Whiting and J. W. M. Whiting 1971; J. W. M. Whiting and B. Whiting 1975; Munroe and Munroe 1975; Munroe et al. 1984).

This paper concerns the behavior of children aged four to fourteen in two groups of !Kung (San) Bushmen. One group lives by hunting and gathering; the other has made a recent transition to settled residence and the tending of crops and small animals. In the foraging group, children are reared by parents (Draper and Harpending 1987). Parents do not systematically delegate authority to older children for the supervision of younger children (Draper 1976). Parents and children show much intimacy and proximity, and children have more or less continuous access to their parents. Parents are highly available both because they are physically present much of the time and because there are no norms of deference or respect that require children to keep their distance from their elders (Draper 1978). Neither boys nor girls have any appreciable responsibility for work.

In the settled group there has been no overt adoption of the practices associated with peer rearing, yet many aspects of life among the settled people have changed in such a way as to create a clear opening for this institution. Parents and children are less physically proximate, and their interactions are fewer. Children do more work, although this is not yet institutionalized. We will show how the economic changes associated with food production among the settled !Kung have led to changes in adult-child interactions reminiscent of those in longer-established and more densely settled agricultural communities.

\section{ETHNOGRAPHIC BACKGROUND}

The !Kung San of the Kalahari Desert, Botswana, have changed in the last 20 or 30 years from nomadic hunting and gathering to settled life supported by gardening and stock raising, supplemented by some gathering (Howell 1979; Lee 1979; Marshall 1976). We use the technique of controlled comparison in analyzing the implications of change for two populations of !Kung. Both groups derive from the same cultural and linguistic population. The sedentary people lived in the !Kangwa Valley of western Botswana and supported themselves by gardening, stock raising and gathering of wild bush foods. They lived in several villages located within about a mile of permanent 
water. The settled !Kung shared their immediate environs (although not their villages) with Herero tribespeople. The latter are a pastoral people of considerable wealth, compared with !Kung, and they sometimes employ !Kung youths as herders. The nomadic !Kung lived 60 to 100 miles south (depending upon season), in the region of the Namibia-Botswana border. Their livelihood was by hunting and gathering.

The contrasts in child life in the two groups appear in several areas: (1) the amount of work done by children, (2) the extent to which the spatial range of children is restricted or enlarged, (3) The increasing differentiation of the behavior of girls and boys, and (4) the proportion of a child's time spent in interaction with adults rather than peers. In order to paint a general picture we will describe the differences between the two groups in brief form, waiting until later to introduce detailed findings.

\section{Bush Camps}

Children living in the nomadic bush camps have spatially restricted ranges, and their social interactions occur primarily in the camp where many other adults and children are close by. A large proportion of their social interactions are with adults, particularly their own parents. Children in the nomadic camps do little work; all of the hunting and virtually all of the gathering is done by adults, while children remain behind in camp, looked after by those adults who are not working on a given day. Although bushliving adults have tasks in camp (processing and cooking food, repairing tools, preparing animal hides), much of the time their hands and their attention are relatively free for socializing. As will be discussed later, adults (particularly women and mothers) focus a great deal of their attention on children (Draper 1975b).

The time of children is largely their own to spend with whom and where they choose. However, the numbers of people in the camps is small (30-40 people), and the distance between different camps is too far (15 to 30 miles) for children to walk. As a result, the effective neighborhood within which children range is quite small. The near bush outside !Kung camps is used by children, but it is unusual for even the older children to stray out of eye and ear shot of the camp. The Kalahari bush is relatively uniform on a scale of several miles; it lacks streams, rock outcrops, caves and other unusual topographic features that would attract prolonged play and exploration by children.

As the bush-living groups move their camps periodically, the physical structures of the camps are rudimentary and few in number. For example, each nuclear family constructs its own grass hut. The huts are arranged in an elliptical pattern, spaced five to twelve feet apart and facing inward. Adults clear the bush around and a few feet in back of the huts and inside the public camp space. This creates a central yard, shared by all, and adults and children spend the great proportion of their time when they are in camp in full view of other people (Draper 1973, 1976, 1978). In this context parents do not assign specific child-minding responsibility to any surrogate, child or adult. 
We do not intend to convey the notion that bush children live in unstimulating environments. Although individual camps are small and homogeneous, children move with their parents several times during the year. On the trek to a new camp children cover large distances and encounter new areas in the regions customarily frequented by their parents. When the new camp site is reached, children encounter a different set of people. This is because all camp members do not usually move together. When a camp breaks up, families of ten relocate for the express purpose of visiting other kin and renewing former acquaintances. Over time, bush children experience substantial variety in social and spatial settings.

It is important to understand the absence of privacy and the permeability of nuclear family residential boundaries in this social setting, the opposite of which is assumed to be not only proper but necessary by members of Western societies of the last hundred or more years (Lasch 1977; Aries 1973). The correspondence between home, residential privacy and nuclear family membership is completely missing for these mobile people. Western scientists who are concerned with the impact of ecological factors on child development consistently stress the importance of privacy and/or stimulus shelter for optimal child development (Altman 1977; Moore and Young 1978; Garbarino 1985; van Vliet and Wohlwill 1985; Wolfe 1978). These recommendations make sense in circumstances in which the family is a spatially bounded and coresidential group. Researchers agree that for modern children who live in typical residential housing, access to private space or outdoor environments is an essential feature of an optimum setting for children.

The ecology of rearing is radically different for mobile !Kung children. Here, life in camp is conducted out of doors in the full view of numerous adults and children. Many camps are physically small enough that people can converse in normal speaking voice while at opposite ends of the camp (Draper 1973). Despite the fact that a small number of related families live in very close proximity in the bush camps, the interactions between adults and children are less widely diffused than might be expected. Parents are disproportionately influential with their children, at least by the measure of who interacts with whom. Data will be presented below that illustrate this point.

\section{Sedentary Villages}

Children living in sedentary villages occupy a different social and physical micro-environment. Most importantly, sedentary adults are busy while they are at home, whereas adults in the bush camps, if they are in camp, are not occupied by tasks to the same extent. Sedentary children have less intimate social contact with adults than bush children, and, because their spatial range is greater, they are more of ten physically distant as well. Much of their social exchange is with peers. The difference in subsistence economy affects what children and their parents are doing.

Perhaps the most visually striking difference between the two settings is environmental. The sedentary villages, while smaller in population $(20-30$ people year round), are internally diverse in terms of physical structures and 
zones that are set aside for specialized uses. For example, the settlement pattern is now a shallow semi-circle of huts facing the stock enclosures, 3040 yards away. The individual huts associated with each family are farther apart and are made of more substantial material (mud with carefully thatched roofs). Separate use areas accumulate around houses, such as drying racks for processing harvested foods and shade arbors that create a comfortable place for adults to sit while grinding corn, repairing tools, etc. The material environment, like the subsistence economy, is more complex and differentiated, mirroring the many necessary activities.

For children, there are many sequelae. As stated earlier, adult attention is preoccupied by daily chores. The ability of adults to monitor the activities of children is reduced not only by economic distractions but by the changed physical environment. Dwellings are spaced farther apart and structures are more substantial and numerous, creating many micro-niches in which children can play away from surveillance and easy call by parents. As in the nomadic camps, daily life is still conducted out of doors and a Western observer viewing settled villagers would be impressed by the lack of privacy and lack of material wealth. However, settled people have moved several steps closer to a distinction between domestic and neighborhood environments that Westerners would find familiar.

Outside the village, the pattern is repeated on a larger scale. There are several villages within a mile or two of the well that is used by all residents of the region. These settlements draw visitors from within and outside the area. During the day both men and women go to other villages. Some adults have employment with Herero neighbors. For example, a few women do milking and milk processing chores for Herero women (at Herero villages) in the season when milk is abundant. !Kung men work on an occasional basis for Herero in roof-thatching and similar chores for which they are likely to be paid in cash. By the ages of seven or eight years, children (alone or with peers) begin to visit locations away from home. Here they encounter an occasional stranger, and other individuals who are not well known to their own parents. In these situations they hear other languages (OtjiHerero and SeTswana). Although the yearly range of children in the settled camps is smaller than that of bush-living children, their experiences are more varied, both socially and spatially.

\section{METHODS}

Data were collected by systematic observation of children in both subsistence groups. Children were observed in a random order chosen at the beginning of each day of observation. Observations took place at intervals throughout the day from 8 a.m. until 6 p.m, and during each observation period a child was observed for ten minutes. Only one ten-minute observation was collected on a given child per day. Before beginning a round of ten-minute observations, the observer (the senior author) waited until any disturbance created by her arrival on the scene had subsided. Because the observer had visited among the sedentary villages for about eight months before beginning the systematic observations, her presence was not disruptive. To the foraging groups, the observer appeared more novel. However, 
repeated visits to the camps of the foragers lessened the strangeness. When visiting in the bush camps, the observer waited until the second and sometimes third day after arriving before beginning the behavior observations. This was done specifically because daily routines were disrupted in the first hours and days of her arrival.

The intent was to observe and record the child's natural behavior with an emphasis on recording his/her activities, the location in which they took place, the whereabouts of the parents, and the people with whom the child associated. Social interaction of a particular sort was also recorded. No attempt was made to record all conversation engaged in by the subject child. Instead, a systematic record was kept of all requests made by the child to another person and requests made of the child by another, where the requests brought about a change in ongoing activity. For example, if a child asked another person for a service, good, or information and the meeting of the request interrupted or brought about a change in the previous activity of the recipient, that interaction was recorded. The same information was recorded if the child was the recipient of such a request. In 187 observations, we recorded 273 requests made by other people to the subject children, and another 189 requests made by the subject children to others. A notational system recorded the identification numbers of the interactants, the nature of the interaction, whether the initial request was complied with, ignored or refused, and whether the request was repeated.

The two types of settings differed in the ease with which observations could be gathered. In the bush camps, children were nearly always available since they did not routinely accompany the women on gathering trips. Occasionally children could not be readily located by the observer, but invariably someone else (either child or adult) knew where the child was. This person could either point or escort the observer to the place where the child (usually in the company of other children) was playing. The percentage of times in which bush children were unavailable for observation was low (3.4 per cent for girls, 2.5 per cent for boys). ${ }^{3}$

In the sedentary villages children frequented a variety of different places and more time was required to locate them, although people were generally helpful and accurate in suggesting where to look. Sedentary children were more frequently unavailable for observation: 9.6 per cent for girls, 12.1 per cent for boys. Children coded as "unavailable" were either absent from the village and too far away to make a search profitable, or could not be located after two attempts by the observer. An analysis comparing the "availability" of bush vs. sedentary children (with sexes combined) is significant $(p=.04$, Fisher's exact test), and will be discussed further below.

In both settings, the observer came to feel comfortable and unobtrusive while conducting the observations. The people themselves are accustomed to living out of doors and to being in full view of numerous other people. It did not take too much training for the observer to make both adults and children understand that when she was "writing on the papers" she could not take part in conversation or ongoing activities. Indeed, adults of ten took it upon themselves to admonish children or adult newcomers not to interrupt the observer while she was working. 
The numbers, ages and distribution of children by subsistence group are given in Table 1. Sedentary children represent a total sample of children who were permanent residents in three villages located near permanent water. Bush children in the sample are a subset of the children in seven camps of the $/ \mathrm{Du} / \mathrm{da}$ area. They were chosen because repeated visits to the region in which their families lived made it clear that they could be found on a reliable basis and therefore were suitable for an observational study in which repeated observations would be made on children's behavior over a period of months. The locations in which the children were found and the constellation of families with whom their parents were living varied over the ten-month period in which the data were collected.

Table 1

Sex, Age, and Subsistence Group of the Subject Children

\begin{tabular}{|c|c|c|c|c|}
\hline & \multicolumn{2}{|c|}{ FEMALES } & \multicolumn{2}{|c|}{ MALES } \\
\hline & Age & N. Obs. & Age & N. Obs. \\
\hline & 4 & 5 & 4 & 2 \\
\hline & 5 & 5 & 5 & 5 \\
\hline & 5 & 4 & 6 & 1 \\
\hline \multirow[t]{16}{*}{ BUSH } & 8 & 4 & 6 & 3 \\
\hline & 8 & 5 & 7 & 4 \\
\hline & 9 & 5 & 8 & 4 \\
\hline & $\underline{14}$ & 1 & 8 & 4 \\
\hline & 7 subjects & 29 obs. & 9 & 2 \\
\hline & & & 12 & 5 \\
\hline & & & 12 & 3 \\
\hline & & & 12 & 2 \\
\hline & & & $\frac{14}{12}$ subjects & $\frac{5}{40}$ obs. \\
\hline & FEMA & & MAL & \\
\hline & Age & N. Obs. & Age & N. Obs. \\
\hline & 7 & 2 & 4 & 6 \\
\hline & 7 & 5 & 4 & 3 \\
\hline & 8 & 4 & 5 & 3 \\
\hline & 8 & 2 & 6 & 3 \\
\hline & 11 & 4 & 7 & 6 \\
\hline \multirow[t]{6}{*}{ SEDENTARY } & 12 & 5 & 10 & 5 \\
\hline & 13 & 4 & 11 & 9 \\
\hline & 13 & 5 & 12 & 12 \\
\hline & 14 & 9 & 12 & 9 \\
\hline & 14 & 12 & 13 & 4 \\
\hline & $\overline{10}$ subjects & $\overline{52}$ obs. & $\frac{14}{11}$ subjects & $\frac{6}{66}$ obs. \\
\hline
\end{tabular}


As Table 1 shows, there were different numbers of children in the two subsistence groups, and different numbers of boys and girls. The number of times a child was observed also varied. Because of the variation in observations per child, we did not use raw observations as the unit of analysis when calculating the average number of minutes of a behavior for each sexsubsistence category. Rather, we compensated for the different numbers of observations per child by calculating an average score (sometimes called a proportion score) for each child. These average (proportion) scores are the units on which Figures 1, 2, and 3 (and the accompanying ANOVA tests) are based." Data on interactions ("requests") were obtained from the ten-minute observations, but were structured differently; for these data (summarized in Figures 4-7), each unit of analysis was an interaction between two individuals, not a ten-minute observation.

\section{RESULTS}

Work

In the sedentary groups, subsistence work is more time consuming. This has important consequences for child socialization, not only because children themselves are put to work (they are, but to a moderate degree) but because much of adult time and attention is preoccupied with making a living. In effect, in the settled villages work is interposed between children and adults and in the process the lives of children are substantially affected.

For the bush-living !Kung, who are hunter-gatherers, conditions in the Kalahari are such that a satisfactory subsistence can be gleaned in only about three days of work in seven (Lee 1979; Draper n.d.). The reduced amount of time devoted to subsistence work in bush camps has a strong effect on the ambience of everyday life. In a typical bush camp one finds a variety of people in camp all day on any given day. Only some adults will be out working; the remainder are at home, resting around a camp fire and keeping informal watch over their own children and the children of absent working parents. There are occasional jobs which the bush-living adults will do at home but such chores take place in camp in the midst of everyday village life.

The opposite is true in the settled villages, where food production and the maintenance activities associated with it appear to take up considerably more time. People, especially women, are busy; their hands are occupied. Conversations revolve around how to accomplish one or the other objective that is usually connected with making a living. The sedentary !Kung say disparagingly of their relatives in the bush, "they have no work." They say of themselves, "we have work," implying that a person of stature has affairs which require attention. Often one enters a settled village and finds no one present except one or two old people and a few children. The adults are away for several hours at a time attending to various chores connected with a complex set of subsistence practices. This difference in work may reflect a widespread pattern; Munroe et al. (1983) argue that labor inputs are moderate in hunting and gathering societies, increase in agricultural societies because of the labor involved in maintaining a large number of goods, and 
then return to moderate levels in industrial societies (but see Minge-Kalman 1980, who argues that labor may be as great in industrial as in agricultural societies, due to an increase in labor time inside the home).

The degree to which children participate in adult labor is also different in the two communities. !Kung in mobile foraging camps do not recruit children into subsistence work for at least two reasons. First, what little work there is can be done most efficiently by adults. Second, the nature of adult work is such that children cannot easily be incorporated into it. This is because in the course of their work both men and women travel out from a camp a distance of several miles, usually over waterless territory. Children lack the endurance to keep up on the march, and should they accompany the adults they would need water and ask to be carried when they grew tired, both of which would increase the load of the working parent. So children stay at home in close proximity to adults, but their time remains their own.

In contrast, children in the settled camps are expected to help adults with their work. Adults are not very systematic or successful in their attempts to get prolonged co-operation from children, probably because the adults themselves were reared as hunters and gatherers and were not indoctrinated at an early age with the importance of obedience and responsibility. (Barry, Child and Bacon 1959). Nonetheless, in the changed setting there are many aspects of the daily routine that easily absorb child labor. The presence of animals (chiefly goats and donkeys) generates a host of chores. When crops are ripe, children can help in harvesting, processing, and storing foodstuffs. In the process of settling down, these !Kung accumulate many more material possessions than their relatives in the bush. They build permanent houses and fences, acquire more tools and baggage -- all of which require maintenance. The sedentary children are put to work, though not in a purposeful fashion, and their lives and relationships with adults take on a tenor that contrasts markedly with that of life in the bush.

We devised codes to measure two types of work: one in which the task lasts a measurable number of minutes, and another in which the work occurs as episodes of behavior too brief to estimate in minutes. The latter category consisted chiefly of episodes of child-tending and miscellaneous errand running. The frequency of such episodes was very low, so we have not tabulated the results here. Work measurable in minutes includes such activities as herding, collecting water, gathering, and processing food. As Figure 1 shows, such work is engaged in far more frequently by boys and girls in the settled camps.

It is likely that these data actually underestimate the difference between the two populations, in part because of the timing of the behavior observations. The observation periods took place between about 8 am and $6 \mathrm{pm}$, yet it was not unusual for the herding work that occupied boys in the settled camps to be done before and after this period, in the very early morning and at dusk. Children also helped in water collecting, yet episodes of such work were less likely to be sampled. The well used by three of the four sedentary communities was about a mile-and-a-half distant. En route for water, children of ten made diversions and were not easily located for observation.

Many cross-cultural studies of child socialization have found that assigning children sex specific tasks is a major way by which cultures shape differences 
in sex role socialization (see reviews in Quinn 1977; Ember 1981; Draper 1985). Task behavior has been shown to affect the degree of egoistic versus prosocial behavior exhibited by children (Ember 1973), their nurturance toward younger children (Edwards and Whiting 1980), and the amount of supervision they receive. In their study of social behavior of children in six societies, Whiting and Whiting (1975) show that girls are typically closer to home, in closer proximity to adults (particularly women) performing chores under close supervision, whereas boys are more likely to be farther from home, interacting with peers and less consistently under supervision. The implications of task behavior suggested by these studies are relevant to !Kung children, as we show below.

Figure 1. Children's Work

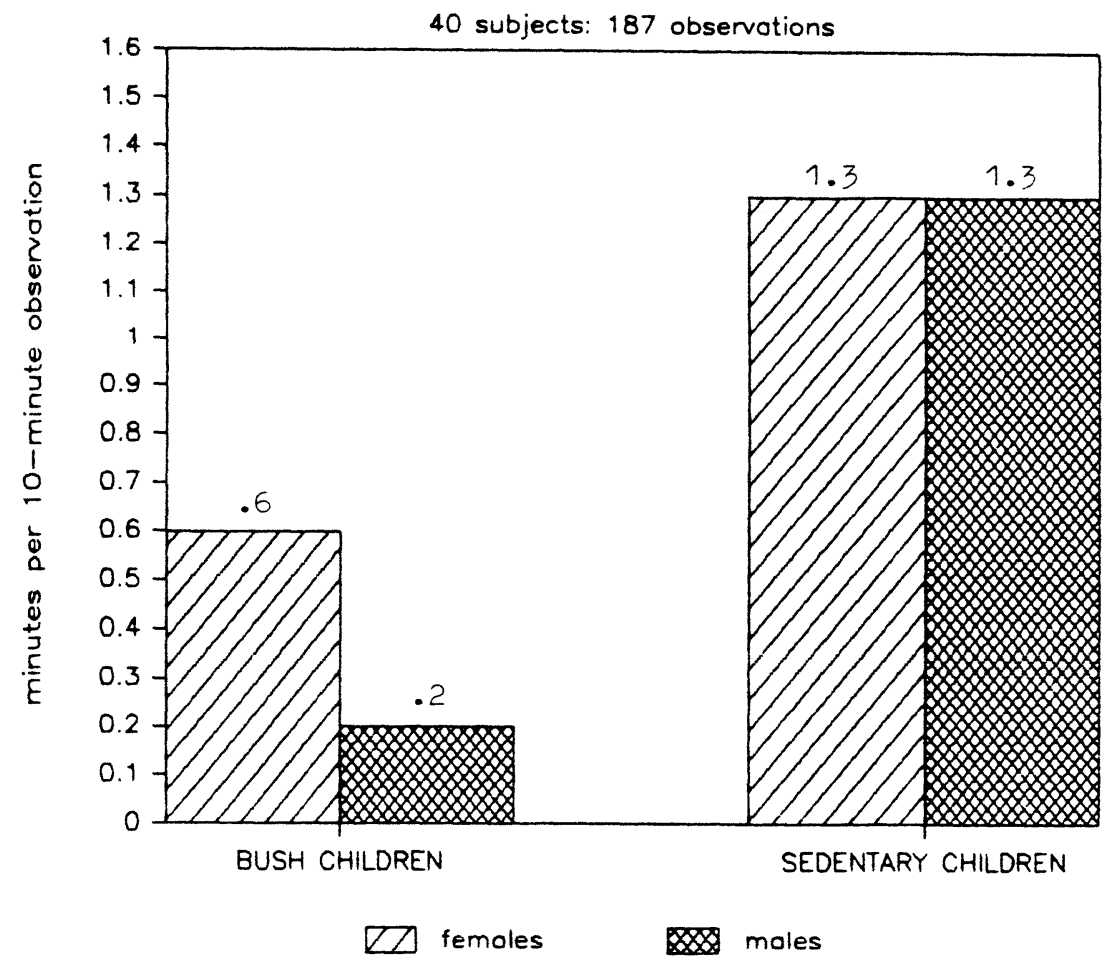

Number of minutes in a ten-minute observation period spent working (gathering, herding, collecting water, or processing food). Effects of subsistence group (bush versus sedentary) and sex were investigated in a two-way ANOVA:

subsistence: $p=.0055$

sex and interaction: n.s.

Spatial Range

As Whiting and Whiting (1975) have indicated, parents influence children not only directly, by teaching and setting examples, but by choices they make 
which influence the social settings in which children spend their formative years (Super and Harkness 1980; Whiting 1980; Weisner 1984). The greater work involvement of children in the settled camps has an important influence on their range and location, since many tasks (especially herding, gathering, and collecting water) take children away from camp. Figure 2 shows the average number of minutes in a ten-minute observation period that children spent in camp.

Figure 2. Minutes in Camp

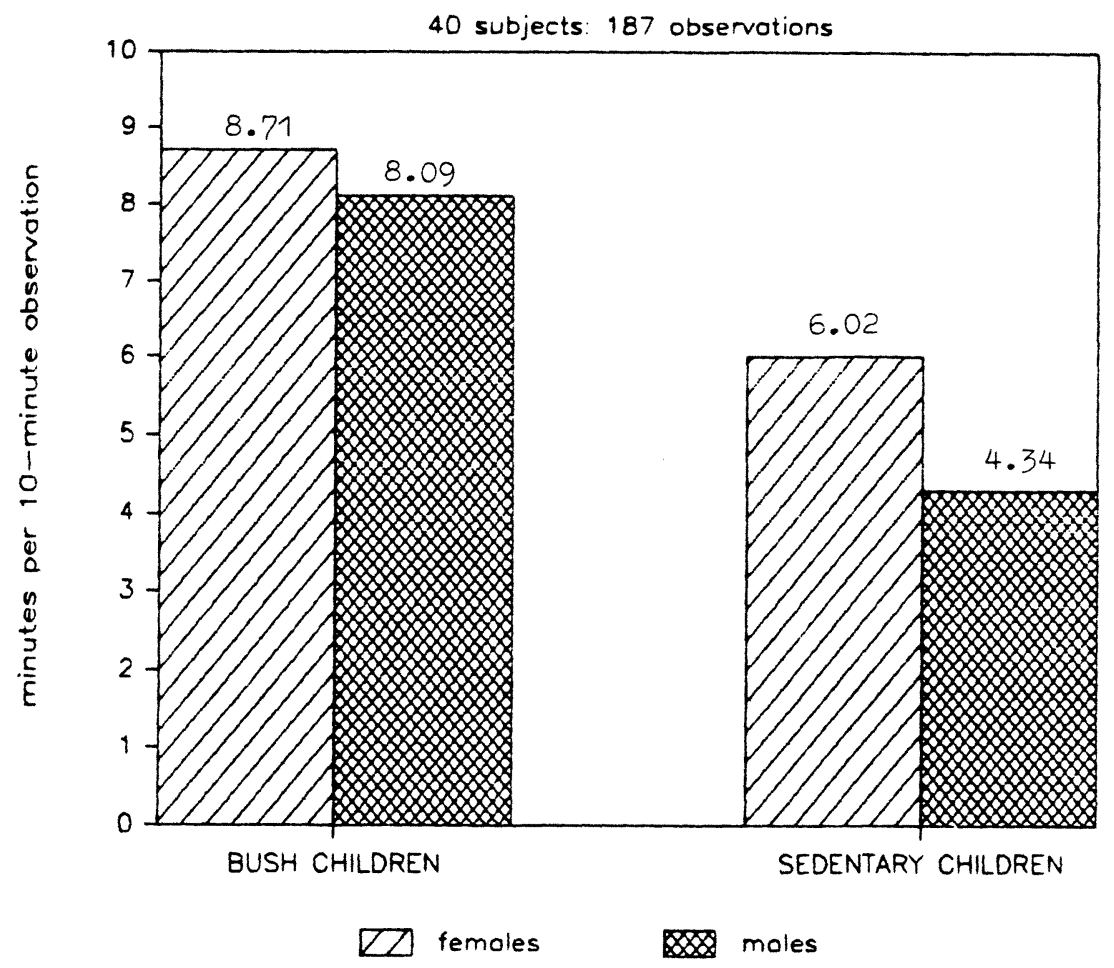

Number of minutes in a ten-minute observation period spent in camp. Effects of subsistence group (bush versus sedentary) and sex were explored in a two-way ANOVA:

subsistence: $p=.0001$

sex: $p=.13$

interaction: n.s.

(one-way ANOVA for sex, sedentary group only: $p=.14$ )

It can be seen that males in the bush camps spent almost twice as much time in camp as did males in the settled camps; the difference for girls, while smaller, was in the same direction. Since it was sometimes not possible to observe children who were out of camp, the real difference in time spent out of camp is greater than Figure 2 indicates. As shown earlier, sedentary children were three to four times more likely than bush children to be unavailable for observation. 
Although work is important, other things encourage children in the settled camps to leave camp more frequently than their cousins in the bush. It is relatively unusual for bush children to stray out of eye and ear shot of the camp. The settled camps, by contrast, are located nearer to other camps (both San and Herero), and there are many things to attract a child's attention.

Sex differences in mobility, with males having larger ranges, have been widely and consistently reported in the literature for both children and adults (see review in Gaulin and Hoffman 1988; Wolfe 1978). While some of this sex difference probably has a biological basis, it can also be influenced by economic factors. Draper (1975b) has shown that the transition to a settled, agricultural way of life has had a marked effect on sex differences in the mobility of !Kung adults. In the bush camps, the activities of gathering and hunting take both women and men away from camp frequently. The picture in the settled camps is very different. Domestic chores keep settled women around the home, busy with the more complex food preparation tasks (including drying and storing) required by agriculture, and the regular upkeep of more permanent structures. Herding and other masculine pursuits take the men out of camp, where they interact with Herero and other outsiders.

Among children, sex differences in range size can also be amplified by participation in sex-appropriate tasks (Munroe and Munroe 1971; Nerlove et al. 1971; Whiting and Edwards 1973). Although we did not measure range size of children, Figure 2 provides suggestive evidence that participation in adult work may increase this difference among !Kung children. Girls and boys in the bush camps spent about the same amount of time in camp, whereas in the settled camps boys were out of camp more frequently than girls were. The sex difference in the settled camps would probably appear larger if the observation periods had included a representative amount of herding activity.

The work of boys was more likely to take them out of camp, away from adults and on their own. Girls tended to stay closer to home unless they were accompanying older women to the water hole to collect water. When women were present during these excursions, action was more purposeful; they filled their buckets with water and returned. The chores of the boys were done in a more leisurely manner, and they were rarely directly supervised by adults. Boys drove the animals to the well, watched them drink, then lingered watching other people who also came to the water. Here the boys heard non-!Kung languages and acquired more information about the larger community. Sedentary girls, like their mothers, inhabited the more restricted space of their own villages or villages nearby. Girls did not have regular chores such as herding, but their mothers of ten gave them small errands (too brief to be measured in minutes) which seemed to have the effect of keeping them close at hand. Boys were likely to be out of sight or far enough away that they could not be enlisted conveniently (Draper 1975b).

\section{Sedentism Increases Contrast Between Sexes In Some Behaviors}

The increased disparity between the lives of male and female children at the settled camps is grounded in economics, but affects many other aspects of 
behavior. We have already discussed how the sex difference in time spent out of camp is magnified in the settled camps. Although both boys and girls do more chores in the settled groups, the types of tasks are different and contribute to increasing the spatial range of boys more than girls. This trend also appears in rough and tumble play and in willingness to comply with requests. As Figure 3 shows, rough and tumble play is equally frequent among children at the bush camps.

Figure 3. Rough and Tumble Play

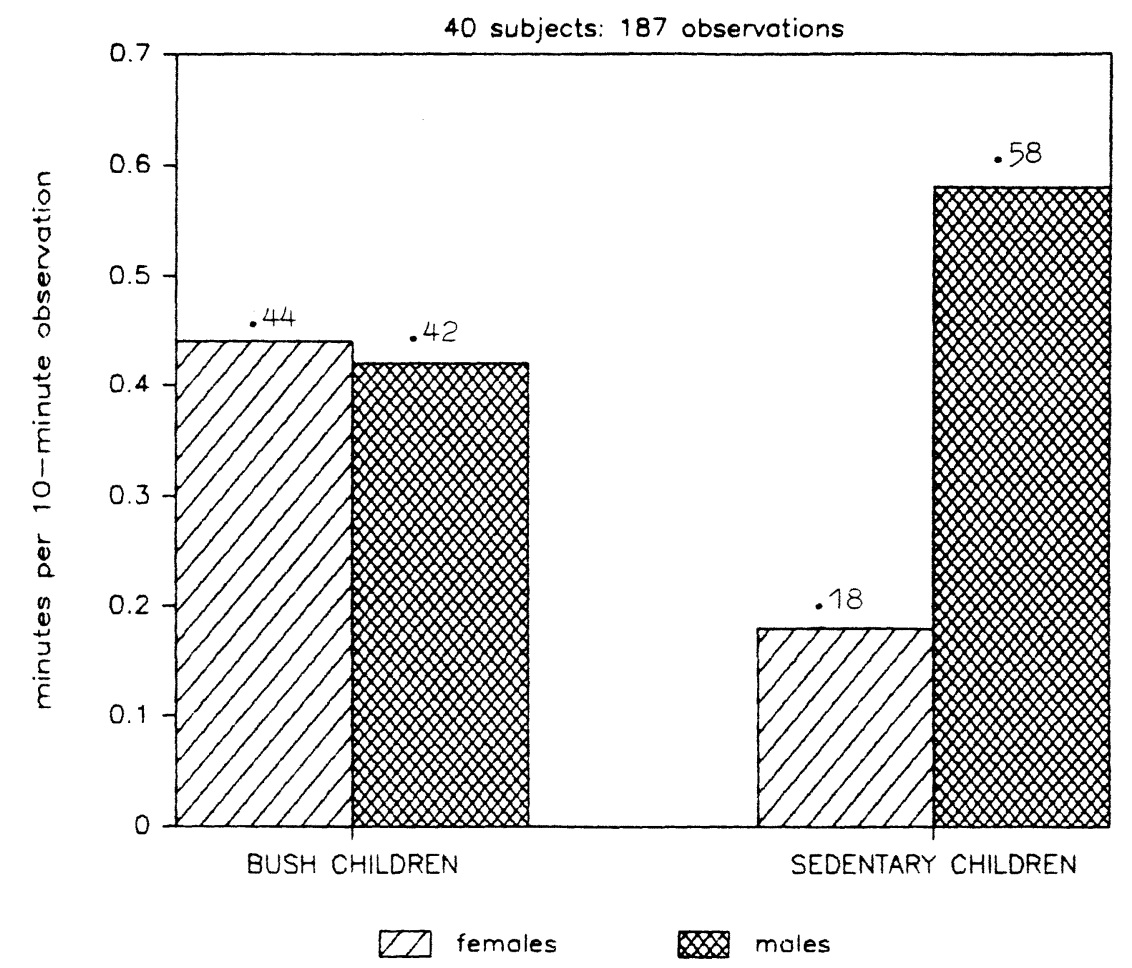

Number of minutes in a ten-minute observation period spent in rough and tumble play. Effects of subsistence group (bush versus sedentary) and sex were explored in a two-way ANOVA:

subsistence: n.s.

sex: $p=$ n.s.

interaction: n.s.

(one-way ANOVA for sex, sedentary group only: $p=.1$ ).

In the settled camps, on the other hand, such behavior increases among boys and is suppressed among girls. Although we cannot verify the point, we expect that roughhousing is discouraged in girls in the settled camps, and that this may be a consequence of their association with younger children and adults. It is consistent with the behavior of adult women in these camps, who 
appeared more restrained and deferent than nomadic women (Draper 1975b). Boys are under fewer physical restrictions; they are under less close adult supervision and their work is more of ten done in the company of other boys close in age.

The number of available playmates may also be a factor in the pattern of rough and tumble play. The absence of any sex difference in this variable in the bush camps is an unusual finding; it may be due not only to the similar lifestyles of boys and girls in the bush camps, but to the small number of available playmates. Children in the bush camps play, of necessity, in mixed-sex, mixed-age play groups. In the sedentary camps there are more villages in the vicinity, and a larger pool of potential playmates.

Figure 4. Response to Adult Requests

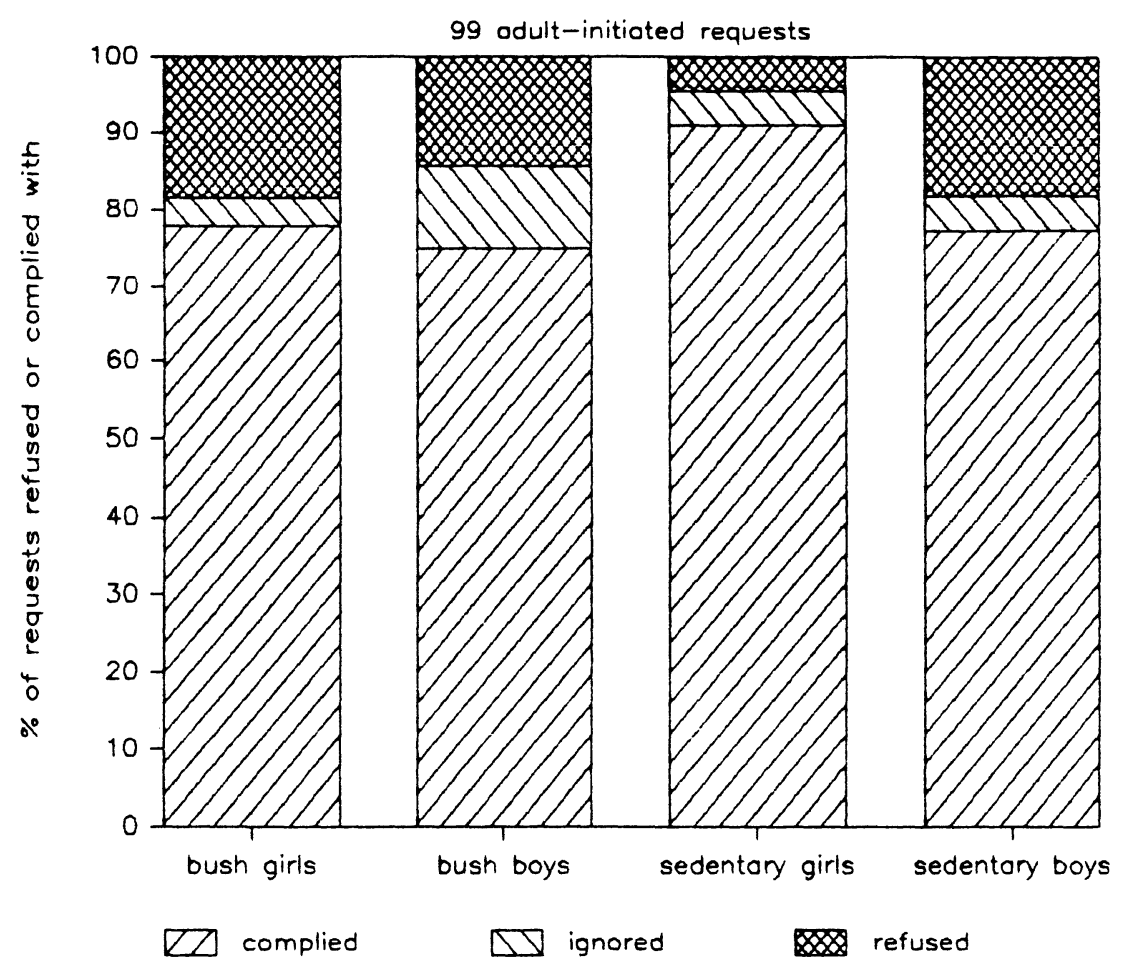

Response of the subject children to requests by adults, indicating the percentage of such requests that were complied with, ignored, and refused.

$p=.17$, Fisher's Exact Test for significant differences between sedentary boys and girls in compliance and refusals.

In order to measure compliance and other aspects of social interaction, we tallied requests made by a child to another person and requests made of the child by other people. In 187 ten-minute observations, 99 requests were recorded in which an adult attempted to obtain some item or concession from 
the subject children. Differences are not statistically significant (the total amount of noncompliance is very small), but Figure 4 suggests a tendency for girls in the settled camps to be less likely than boys to refuse adult requests outright, and more likely to comply with them. Mobile girls and boys are clearly similar in this regard, their rate of compliance being similar to that of the sedentary boys. The sex difference in the settled camps for these variables is at best only marginally significant, so any conclusions must be tentative. However, the pattern of such differences appears to us indicative of how the changed setting of sedentary life affects the behavior of girls and boys differently.

\section{Social Interactions: Requests to and from Children}

Another area of contrast between the two subsistence groups concerns the types of individuals with whom children interact. We explored this aspect of interaction with the same data used to measure compliance. Earlier, we indicated that the level of interaction with adults was higher for children in nomadic than in sedentary groups (see Figure 5).

Figure 5. Requests from Adults vs. Children

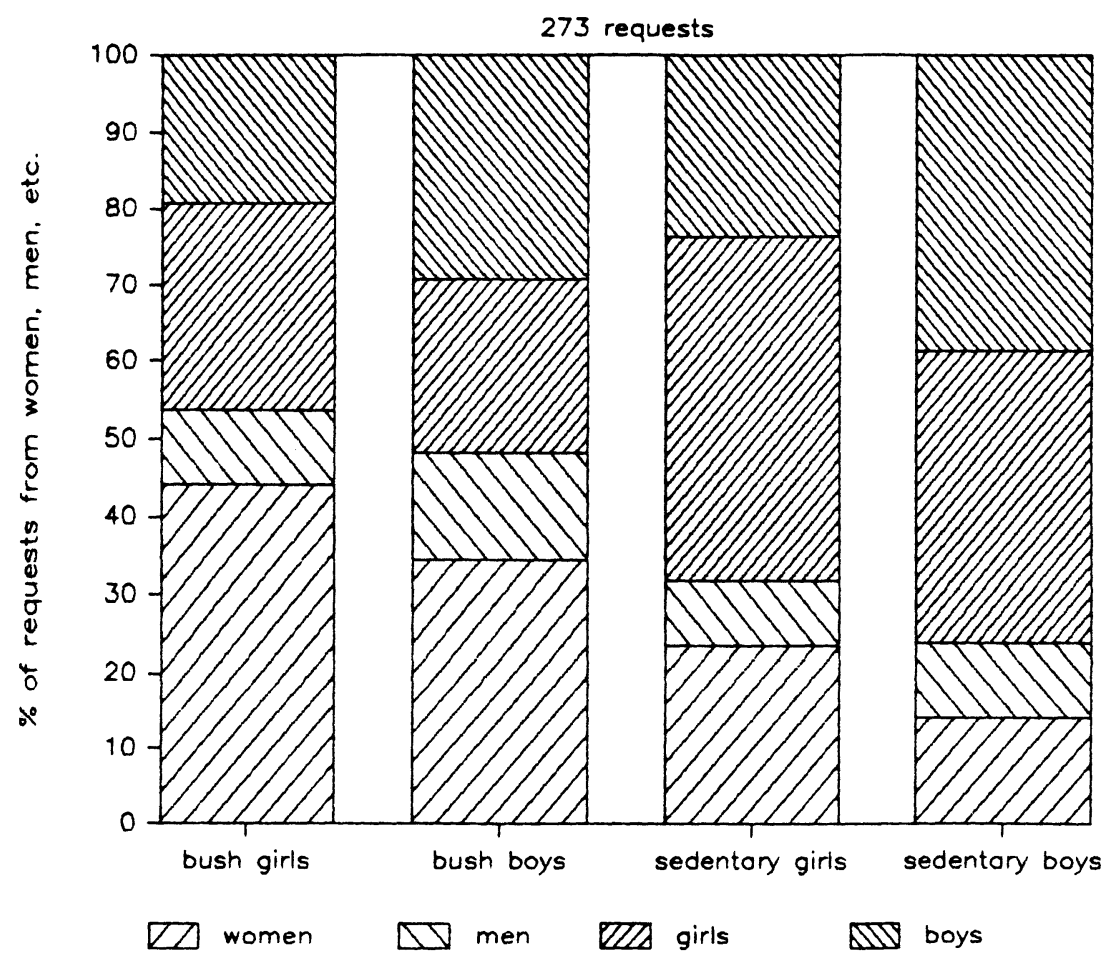

Percentage of requests directed to the subject children from women, men, other girls, and other boys.

$p=.003$, chi-square test for comparison of requests to four groups of subject children by women, men, girls, and boys. 
Combining adults of both sexes, we can see a substantial difference in the frequency with which adults in the two groups initiate requests to children. Bush girls and bush boys received about half of their requests from adults (54 per cent for girls, 48 per cent for boys), whereas for sedentary children the percentage of requests received from adults is only 32 per cent for girls and 24 per cent for boys. In other words, adults in the nomadic groups figure prominently in the social interactions of children, the percentage of requests being approximately double that for sedentary children.

The same pattern emerges when we consider the patterning of childinitiated requests, although the number of requests directed by children to adults is very small for both groups (see Fgure 6). Children in the bush camps made a greater percentage of requests to adults than did children in the sedentary camps (three times greater for girls, two times greater for boys).

Figure 6. Requests to Adults vs. Children

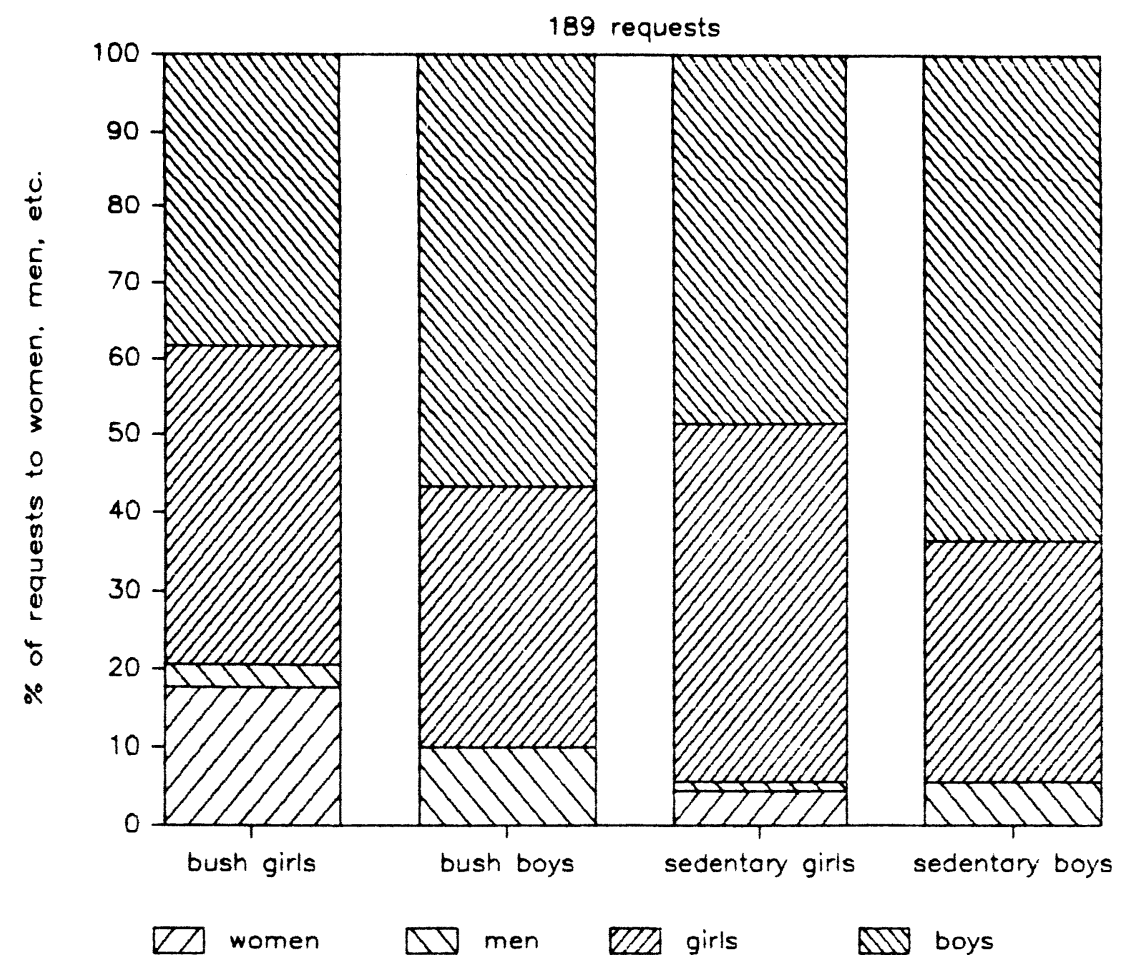

\footnotetext{
Percentage of requests directed by the subject children to others -. women, men, other girls, and other boys.

$p=.003$, chi-square test for comparison of requests from four groups of subject children to women, men, girls, and boys.
} 
Figure 7 shows that bush girls receive about three times as many requests from their parents as from other adults, and males in both groups receive about twice as many. The fact that parents in bush-living groups are so directive toward their children, in comparison with other adults, is interesting given both the close spatial proximity among individuals in the foraging camps and the close connections of kinship and marriage among them. In spite of the fact that, from the point of view of an adult, everyone's children are constantly underfoot, parents (especially mothers) selectively attend to their own children, meanwhile by-passing nieces, nephews, cousins and sometimes their own younger siblings and a variety of other close kin.

Figure 7. Requests from Parents vs. Other Adults

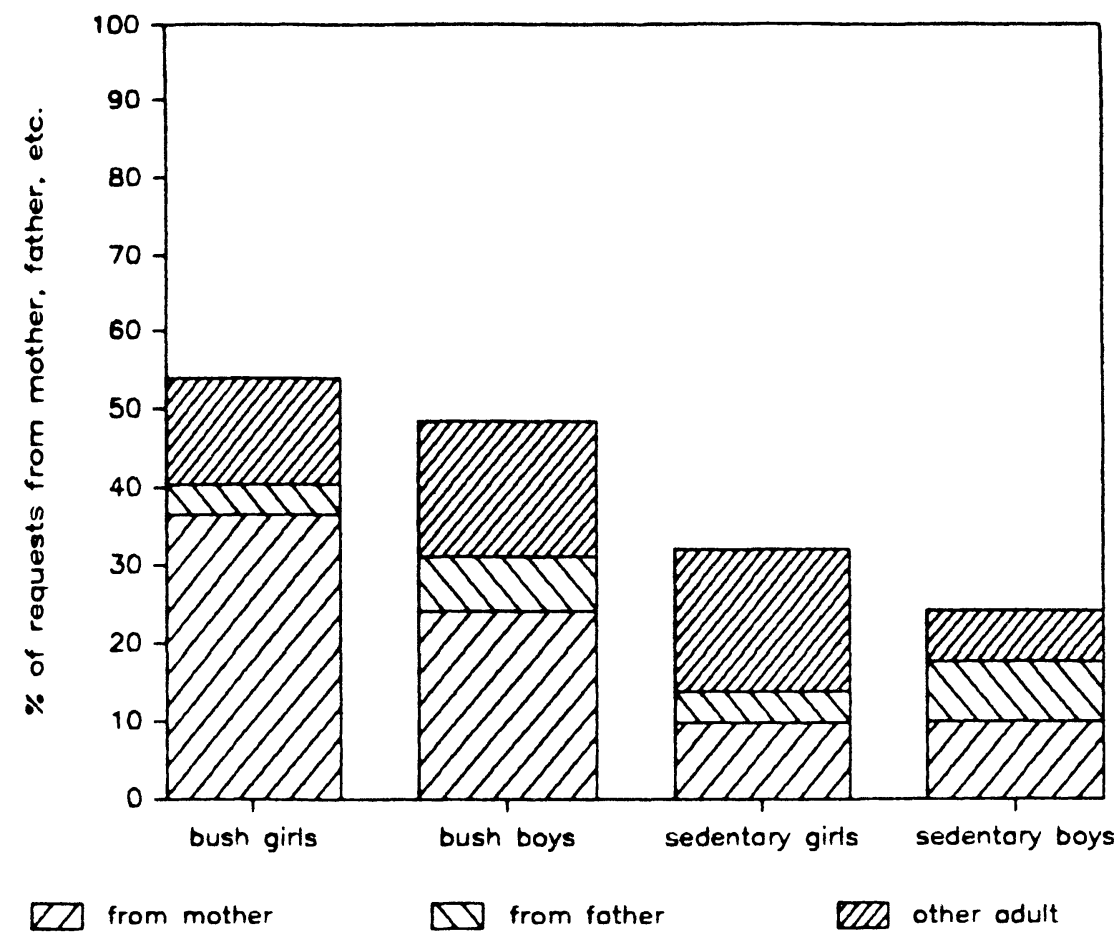

Percentage of requests directed to the subject children from mothers, fathers, and other adults.

Figure 7 also shows how maternal attention becomes eroded in the settled camps. Among both sexes, the percent of requests received from mothers declines with sedentism. While the number of parent-child interactions is small, these data are shown because they demonstrate that it is not only adult/child interactions that are reduced among sedentary people, but mother/child interactions as well.

Thus far, we have described the pattern of interaction by showing the percentage of requests that children of a given sex and subsistence group 
receive from individuals of various categories. This indicates whether children have a greater proportion of their interactions with adults or children, with males or females, and so on. One might also want to know whether a particular set of individuals issued more requests, in an absolute sense, to boys or girls, bush or sedentary children, and so on. Because there are different numbers of observations on children in the different groups, Figures 5-7 do not indicate this directly. However, it can easily be calculated by dividing the number of requests by the number of observations, as given in Table 1. We have done this for the findings discussed above, and have found that the qualitative nature of the sex and subsistence differences remain unchanged.

\section{DISCUSSION AND CONCLUSIONS}

Our data show a pattern of differences in the behavior and social interactions of children in foraging and sedentary groups. We will discuss next the probable significance of these differences for the integration of children into two different economies.

\section{Integration of Children in Bush Camps}

The children of the foraging camps are seldom called upon to work, either as babysitters or as assistants to adults in their daily tasks. We discussed previously the biological, ecological and economic constraints that account for this. Mothers are the primary caretakers of infants and toddlers. Because of long breast feeding (three or more years) mothers take young children with them on gathering trips. Children are nursed during the day and given snacks (sometimes premasticated) from the foods the women gather. Thus, these youngest children are not left at camp under the care of surrogates (either children or adults) while the mothers work. The work that women do takes them far from camp, making it impossible to return and nurse their babies. !Kung lack suitable infant foods, such as gruel and fruit mashes, which can be used to supplement the diet. The solution is to carry nurslings during the day treks.

It is less clear why women are not more creative in figuring out ways to leave toddlers behind, for these children eat adult food and could get by without breast milk for the six to ten hours that women are away from camp. Since about half of the adults stay in camp on a particular day, there are adequate personnel to supervise. When asked why they do not leave toddlers behind, !Kung explain that the children will not tolerate it, and indeed toddlers display prodigious temper tantrums when the time comes for the mothers to deliberately wean them from nursing and back carrying. (This is usually begun when the mother realizes she is pregnant.)

The remarkable indulgence of !Kung mothers, evidenced in their willingness to carry toddlers long distances and to provide for older children who do no work, is especially puzzling in light of recent findings about the Hadza. Although this East African foraging society resembles the !Kung in many aspects of social and economic organization, parental investment appears to be much lower in Hadza society. Blurton Jones et al. (1988) 
indicate that Hadza children are weaned at an earlier age, and mothers regularly leave toddlers behind in camp (in spite of bitter protests) even though there may be few or no adults in camp to look after them. This is surprising, since Hadza adults spend considerably more time out of camp gathering and hunting than do !Kung adults (Hawkes et al. 1988; Blurton Jones et al. 1988), hence they probably have even fewer alternate adult caregivers available. It has been argued that the energetic costs of child transport make the four year birth spacing of the mobile !Kung optimal for reproductive success (Lee 1972; Blurton Jones and Sibly 1978; Blurton Jones 1986; but see Pennington and Harpending n.d. for contradictory findings).

Yet it is not clear why these transport costs are undertaken. Finally, Hadza children, unlike !Kung children, are productive gatherers in their own right; Blurton Jones et al. (1988) estimate that Hadza children are supplying approximately half of their calories through their own gathering efforts.

When !Kung mothers are not gathering on a given day, they remain the primary providers of comfort and food for young children. Women, of course, are not entirely idle during the days at camp. They cook food, repair clothing, make jewelry, collect water, and repair huts. These are the kinds of tasks, however, that can be executed by one person in a leisurely manner with many stops and starts to accommodate interruptions from other camp residents, including children. With the exception of water collecting, which among foragers took one to two hours per day, there were few activities that took adults away from camp and close proximity to their children on those days when they were not gathering or hunting. In this setting, there is little incentive to increase efficiency of production by organizing the timing or sequence of tasks, or to regulate participation by different personnel. Children of all ages, consequently, have direct access to adults, especially parents. Adults do not make children peripheral in order to protect their own time, energy, or work schedules.

Children in camp spend a great deal of time in each other's company, but mothers do not delegate care of younger to older children. This is reflected in the small amount of work performed by children in the foraging camps. Parents deal directly with older children, the four to fourteen year-olds who are the subject of this paper. This intense parental involvement is apparent in our interaction data. Bush children receive about half of their requests from adults, and parents (especially mothers) initiate most of these.

To summarize, this is a system of "parent rearing," but one generated by a very different set of ecological circumstances from that found in industrial societies, where this pattern of child rearing is also found. Among modern Western families, the intense parent-child bond is, in part, an outcome of the trend to nuclear family households, the privacy of domestic life, and high geographical mobility that separates parents and consanguineal kin. Western middle-class children are characteristically extremely demanding of parental attention in comparison with children in traditional societies of the peerrearing type. The intrusive style of Western children surely derives in part from the absence of alternative interactants in isolated, nuclear families. Among the mobile !Kung, parent rearing exists in a context of close interaction with other band members. This may be why !Kung bush children 
initiate relatively few interactions with adults (Figure 6), even though adults are physically available and not preoccupied with other tasks.

\section{Integration of Children in Settled Villages}

The recently-settled !Kung have adopted an economy based on food production rather than food gathering. This transformation, which has occurred independently in many areas of the world, has historically been associated with a series of institutional changes: a rise in fertility and population size, larger settlements, increased labor requirements, larger domestic units, more hierarchical authority patterns, increased sexual division of labor, greater use of child labor, and greater differentiation among individuals, of ten reflected in the development of local leadership roles and polygynous marriages.

The settled !Kung have made only modest progress in the direction of either independent food production or the traits listed above. They were by no means affluent, and women continued to supplement the diet with gathered food. Many villagers, for example, still lived in grass huts constructed in the manner of the foragers. Stock ownership was limited to small numbers of goats per family. A few individuals owned donkeys, but accumulation of horses and cattle was beyond their means, though many aspired to become milk-drinking cattle owners. Families were still nuclear and based on monogamous marriages, and villages remained small. People were planting gardens on a small scale, without the help of oxen-drawn plows employed by Herero or Tswana villagers in the region. Children were not systematically put to work by their parents, though they were observed to work more than children in the bush groups. The familiar pattern of delegating the care of younger to older children had not developed despite the fact that parents appeared to be working more hours in a day than adults in the bush camps, and were frequently away from camp for hours at a time.

Yet the behavior of children, as measured by a series of ten-minute behavior observations, had changed in a direction that begins to approximate that of children in societies with longer traditions of settled food production, sex-role differentiation and peer-rearing. Children were increasingly involved in interactions with peers, though not as caretakers. Children were more distant from adults, both in terms of interactions and in terms of physical proximity. Sedentary parents initiated fewer interactions with children; in large measure this was because their work of ten took them out of the village, or was more time-consuming and demanding so that they were less able to keep close watch on children. The sedentary children were also less available for such interaction, since they spent more time out of the village.

How might these developments in the daily routines of children promote further institutional and normative changes in the society? Our predictions are speculative at this point, but other researchers have worked with settled !Kung in the years since these data were gathered. Many of these suggestions can be evaluated with more recent data, some of which will be collected by the authors in the near future. 
We suggest that child labor increasingly will be required, both to care for younger children and to assist with adult work. As adult tasks become more differentiated and numerous, with cattle herding and gardening being undertaken on a larger scale, child labor will be coerced more efficiently. This, and the increased separation of parents and children, should lead to less intimate and more authoritarian relations between the generations.

Hand in hand with the recruitment of child labor goes a decrease in the net cost to parents of each child. More distal relations between parents and children, furthermore, reduce the ability of the child to put demands on the parent for attention, nurturance, or services. The decrease in parental investment in each child is likely to lead to increases in fertility. The evidence for fertility change is equivocal at present, with Lee (1979) finding shorter birth spacing in sedentary !Kung communities and Harpending and Wandsnider (1982) finding no differences. We expect such changes, if they exist now at all, to become greater as parents become able to make systematic use of their children's labor, and as the use of such labor becomes institutionalized.

While we interpret the behavior of children in the settled villages as moving toward a pattern typically found among agricultural communities, we do not mean to imply that change in child behavior and socialization will necessarily follow a unilinear path as societies increase in intensity and complexity of production. The contrast in maternal and child behavior among the !Kung and the Hadza is sufficient caution in this regard. Rather than an exclusive focus on broad taxonomic categories (hunter-gatherers, cultivators, industrial societies), further progress is likely to come from close attention to the costs and benefits to individuals of particular parenting strategies. For example, how do different strategies affect the relative productivity of adult to child labor? How do the opportunity costs of childcare differ for people of different ages? What are the marginal returns (in child health, survivorship, etc.) from childcare, and from different kinds of parental investment (for example, provisioning vs. direct supervision)? Let us consider the first of these variables as an example. We have suggested that !Kung children in the settled camps do more work both because their help is needed more and because of the types of tasks associated with a food-producing economy. Because these include many maintenance tasks, which can of ten be performed close to home, they can more easily absorb child labor. This should make the productivity of child labor, relative to that of adults, higher in this context. It is quite likely that this will of ten be the case as foragers adopt food production, but this variable will also be affected by local circumstances. The Hadza gather closer to camp than do the San (Hawkes et al. 1988; Blurton Jones et al. 1988), perhaps because the !Kung environment is patchier. To the extent that gathering close to camp is more productive, we can expect that the returns to labor for children, who cannot walk long distances, will be higher. Under these circumstances, child labor may be adaptive even in a hunting and gathering economy (see Blurton Jones et al. 1988). 


\section{Sex Differences}

The socio-economic changes associated with incipient food production have interesting implications for sex differences. Because children in the mobile foraging camps do little or no work, and because the small size of the camps makes mixed-sex, mixed-age play groups the norm, girls and boys grow up in similar social and physical settings. It is not surprising, therefore, that among the mobile!Kung most of the behaviors we measured show little or no sex difference. Girls and boys of the sedentary groups, on the other hand, show increased sex differentiation in behavior. For example, the amount of rough and tumble play is similar for bush children of both sexes, whereas in the sedentary groups such play is less frequent for girls than for boys. Rough and tumble play may be more frequent among the boys because they are more likely to be away from camp, remote from adults and physical settings where rough play would be discouraged (Lott and Hart 1977). This sex difference will probably become greater as child work becomes more regular and institutionalized, and as girls become differentially involved in caring for younger children.

Sedentary boys are out of camp more than girls, and as a result are likely to acquire more knowledge and experience of extra-village events. Elsewhere, Draper (1975b) has pointed out that !Kung men and women differ in similar ways. For example, sedentary men were away from the home village, women were home bound; men were likely to be employed by non-Bushmen away from their home village, women were not; men were more proficient at nonBushman languages, women less so; men were moving into positions of political control and were informally recognized as heads of villages and families, women were not. It is intriguing to observe the changes in children's behavior in the context of these adult role changes.

Although sedentary girls were not expected to perform as child nurses, data from the social interactions suggest that they may be making a degree of accommodation to changing adult work loads not seen in the boys. For example, sedentary girls receive slightly more requests from adults than do boys, and may show more compliance and fewer refusals to adult requests. This may be an outcome of the girls' restricted range (they are in the village more than the boys), since this places them under closer adult supervision. This situation promotes closer shaping of the behavior of girls than of boys (Draper 1975a). We mentioned earlier that girls' chores such as watercollecting were of ten carried out with adult women whereas boys did not do their herding chores in the company of men. The girls and boys are being drawn into different socialization environments that are consonant with the adult roles of their group and with what we expect will be the shape of things to come, given the characteristics of other, more elaborated foodproducing systems.

Most social science analyses of culture change are primarily descriptive and point out the ways in which social systems differ, or illustrate how the same system can be organized differently at different stages of its transformation. We report a type of data collection, analysis, and interpretation that focuses on the behavior of individuals. We identify changes in the behavior of 
individuals, and make a case for the influence of these behavioral changes for future socio-cultural change in !Kung society.

\section{NOTES}

1. These data were collected in 1968 and 1969 in research funded by the National Institutes of Mental Health (Grant no. 13611) to Irven DeVore and Richard Lee. Analysis of the data was supported by a faculty research grant from the University of New Mexico.

2. For example, people preparing to hunt, gather or collect water cancelled their plans when the opportunity arose to debrief the anthropologist about the news in distant places, to watch her set up her tent and offload gear.

3. On the rare occasions when children were unable to be observed, it was because they were away with the mother or father in the course of gathering or hunting. These percentages also indicate the low frequency of participation by children in adult subsistence work.

4. In computing sums of squares, each child's contribution was weighted by the number of observations on that child. Provided that the observations are statistically independent, this minimizes the sampling variance of our estimate of the mean (Brownlee 1965:95-97) and satisfies the homoschedasticity assumption of analysis of variance (Rao 1973:221). Some variables were not normally distributed, however, so significance values should be interpreted with caution. Data on interactions ("requests") were obtained from the ten-minute observations, but were structured differently; for these data (summarized in figures 4-7), each unit of analysis was an interaction between two individuals, not a ten-minute observation.

5. Boys were expected to bring the animals in by early evening but often failed to do so. Occasionally when night had almost arrived one or more or the men would discover that the goats had not been corraled. Shouts were heard, "Where are the boys? Call them to do the animals!" The men themselves hastened into the near bush, found the goats grazing nearby and drove them into the village, meanwhile scolding the boys loudly. Children were not beaten or severely chastized for such failures, despite the fact that lion and hyena regularly killed stock, particularly when they were left out at night.

6. In a retrospective study of survivorship of children born to !Kung women past childbearing age, Pennington and Harpending (n.d.) found that there was no relationship between lifetime fertility and survival of offspring. This finding contradicts the hypothesis that !Kung women maximize fitness by increasing birth spacing, since this hypothesis implies that mortality of offspring should increase, above a threshold of four or five, with sibship size. There was no evidence of such an increase in a sample of approximately 600 live births.

\section{BIBLIOGRAPHY}

Altman, I. 1977. Privacy Regulation: Culturally Universal or Culturally Specific. Journal of Social Issues 33:66-84.

Aries, P. 1973 (1962). Centuries of Childhood. Harmondsworth, England.

Barry, H., I. Child, and M. Bacon. 1959. The Relation of Child Training to Subsistence Economy. American Anthropologist 61:51-63.

Berry, J. W. 1967 Independence and Conformity in Subsistence Level Societies. Journal of Personality and Social Psychology 7:415-18.

Blurton Jones, N. G. 1986 Bushman Birth Spacing: A Test for Optimal Interbirth Intervals. Ethology and Sociobiology 7:91-105. 
Blurton Jones, N. G., K. Hawkes and J. O'Connell 1988. Measuring and Modelling Costs of Children in Two Foraging Societies. Comparative Socioecology of Mammals and Man. eds. R. Foley and V. Standen (in press). London.

Blurton Jones, N. G, and R. M. Sibly. 1978. Testing Adaptiveness of Culturally Determined Behaviour: Do Bushman Women Maximise Their Reproductive Success by Spacing Births Widely and Foraging Seldom? Human Behaviour and Adaptation. Symposium No. 18 of the Society for Study of Human Biology, eds. N. Blurton Jones and V. Reynolds, pp. 135157. London.

Borgerhoff M., M. and M. Milton. 1985. Factors Affecting Infant Care in the Kipsigis. Journal of Anthropological Research 41:231-262.

Brownlee, K. A. 1965 Statistical Theory and Methodology in Science and Engineering (Second Edition). New York.

Draper, P. 1973. Crowding among Hunter Gatherers: the !Kung Bushmen. Science Vol. 182, No. 9109, 301-303.

1975a. Cultural Pressure on Sex Differences. American Ethnologist 2:602-616.

1975b. IKung Women: Contrasts in Sex Role Egalitarianism in the Foraging and Sedentary Contexts. Toward an Anthropology of Women, ed. R. Reiter, pp. 77-109. New York.

1976. Social and Economic Constraints on IKung Childhood. Kalahari Hunter Gatherers, eds. R. B. Lee and I. DeVore, pp. 200-217. Cambridge.

1978. The Learning Environment for Aggression and Anti-Social Behavior. Teaching NonAggression, ed. A. Montagu, pp. 31-53. New York.

1985. Two Views of Sex Differences in Socialization. Male-Female Differences: A BioCultural Perspective, ed. R. L. Hall, pp. 5-25. New York.

n. d. IKung Work Effort.

Draper, P., and H. Harpending. 1987. Parent Investment and the Child's Environment. Parenting Across the Life Span: Biosocial Dimensions, eds. J. B. Lancaster, A. S. Rossi, J. Altmann and L. R. Sherod, pp. 207-225. New York.

Edwards, C. P., and B. B. Whiting. 1980. Differential Socialization of Girls and Boys in Light of Cross-Cultural Research. New Directions for Child Development 8:45-57.

Ember, C. 1973. Feminine Task Assignment and the Social Behavior of Boys. Ethos 1:424-39. 1981. A Cross-cultural Perspective on Sex Differences. A Handbook of Cross-Cultural Human Development, eds. R. H. Munroe, R. L. Munroe, and B. B. Whiting, pp. 531-580. New York.

Gaulin, S., and H. Hoffman. 1988. Functional Significance of Sex Differences in Spatial Ability. Human Reproductive Behavior: A Darwinian Perspective, eds. L. Betzig, P. Turke, and M. Borgerhoff-Mulder, pp. 129-152. Cambridge.

Garbarino, J. 1985. Habitats for Children: An Ecological Perspective. Habitats for Children: The Impacts of Density, eds. J. F. Wohlwill and W. van Vliet, pp. 125-143. Hillsdale, NJ.

Harpending, H., and L. Wandsnider. 1982. Population Structures of Ghanzi and Ngamiland !Kung. Current Developments in Anthropological Genetics II, ed. M. Crawford, pp. 29-50. New York.

Hawkes, K., J. O'Connell, and N. Blurton Jones. 1988. Hardworking Hadza Grandmothers. Comparative Socioecology of Mammals and Man, eds. R. Foley and V. Standen (in press). London.

Howell, N. 1979. Demography of the Dobe Area!Kung. New York.

Konner, M. J., and C. Worthman. 1980. Nursing Frequency, Gonadal Function, and Birth-Spacing among !Kung Hunter-Gatherers. Science 207:788-791. 
Lasch, C. 1977. Haven in a Heartless World: The Family Besieged. New York.

Lee, R. B. 1972. Populations Growth and the Beginnings of Sedentary Life among the !Kung Bushmen. Population Growth: Anthropological Implications, ed. B. Spooner, pp. 329-342. Cambridge.

1979. The IKung San: Men, Women, and Work in a Foraging Society. Cambridge.

Leiderman, P., H., and G. F. Leiderman. 1974. Affective and Cognitive Consequences of Polymatric Infant Care in the East African Highlands. Minesota Symposia on Child Psychology 8:81-110.

1977. Economic Change and Infant Care in an East African Agricultural Community. Culture and Infancy: Variations in the Human Experience, eds. P. H. Leiderman et al., pp. 405-438. New York.

LeVine, S., and R. A. LeVine. 1981. Child Abuse and Neglect in Sub-Saharan Africa. Child Abuse and Neglect: Cross-Cultural Perspectives, ed. J. E. Korbin, pp. 35-55. Berkeley.

Lott, D. F., and B. L. Hart. 1977. Aggressive Domination of Cattle by Fulani Herdsmen in Relation to Aggression in Fulani Culture and Personality. Ethos 5:174-68.

Marshall, L. 1976. The !Kung of Nyae Nyae. Cambridge.

Minge-Kalman W. 1980. Does Labor Time Decrease with Industrialization: A Survey of Time Allocation Studies. Current Anthropology 21:279-87.

Moore, R., and D. Young. 1978. Childhood Outdoors: Toward a Social Ecology of the Landscape. Children and the Environment, eds. I. Altman and J. F. Wohlwill, pp. 83-130. New York.

Munroe, R. L., and R. H. Munroe. 1971. Effect of Environmental Experience on Spatial Ability in an East African Society. The Journal of Social Psychology 83:15-22.

1975. Levels of Obedience among U. S. and East African Children on an Experimental Task. Journal of Cross-Cultural Psychology 6:498-503.

1980. Perspectives Suggested by Anthropological Data. Handbook of Cross Cultural Psychology, Vol. 1., eds. H. C. Triandis and W. W. Lambert, pp. 253-317. Boston.

1984. Infant Experience and Childhood Performance. Ethos 12:291-309.

Munroe, R. L., R. H. Munroe, C. Michelson, A. Koel, R. Bolton, C. Bolton. 1983. Time Allocation in Four Societies. Ethnology 22:355-70.

Munroe, R. H., R. L. Munroe, and H. S. Shimmin. 1984. Children's Work in Four Cultures: Determinants and Consequences. American Anthropologist 86:369-379.

Nerlove, S., R. Munroe, and R. Munroe. 1971. Effect of Environmental Experience on Spatial Ability: A Replication. The Journal of Social Psychology 84:3-10.

Ochs, E. 1982. Talking to children in Western Samoa. Langauge in Society 11:77-104.

Pennington, R., and H. Harpending. (n. d.) Fitness and Fertility among Kalahari !Kung (ms.), Department of Anthropology, Pennsylvania State University.

Quinn, N. 1977. Anthropological Studies on Women's Status. Annual Reviews in Anthropology 6: $181-225$.

Rao, C. R. 1973. Linear Statistical Inference and Its Applications (second edition). New York.

Scheper-Hughes, N. 1985. Culture, Scarcity, and Maternal Thinking: Maternal Detachment and Infant Survival in a Brazilian Shantytown. Ethos 13:291-317.

Smith, P. K. 1980. Shared Care of Young Children: Alternative Models to Monotropism. MerrillPalmer Quarterly 26:371-389.

Stone, L. 1977. The Family, Sex and Marriage in England 1500-1800. New York.

Super, C., and S. Harkness. 1980. New Directions for Child Development: Anthropological Perspectives on Child Development. San Francisco.

van Vliet, W., and J. F. Wohlwill. 1985. Habitats for Children: The State of the Evidence. Habitats for Children: The Impacts of Density, eds. J. F. Wohlwill and W. van Vliet, pp. 201-229. Hillsdale, NJ. 
Weisner, T. S. 1984. The Social Ecology of Childhood: A Cross-cultural View. Beyond the Dyad, ed. M. Lewis, pp. 43-58. New York.

1987. Socialization for Parenthood in Sibling Caretaking Societies. Parenting Across the Life Span: Biosocial Dimensions, eds. J. B. Lancaster, A. S. Rossi, J. Altmann and L. R. Sherod, pp. 237-270. New York.

Weisner, T., and R. Gallimore. 1977. My Brother's Keeper: Child and Sibling Caretaking. Current Anthropology 18:169-190.

Whiting, B. B. 1980. Culture and Social Behavior: A Model for the Development of Social Behavior. Ethos 8:95-116.

Whiting, B. B., and C. Edwards. 1973. A Cross-Cultural Analysis of Sex Differences in the Behavior of Children Aged Three through Eleven. The Journal of Social Psychology 91.

Whiting, B., and J. W. M. Whiting. 1971. Task Assignment and Personality: A Consideration of the Effect of Herding on Boys. Comparative Perspectives on Social Psychology, eds. W. W. Lambert and R. Weisbrod, pp. 33-45. Boston.

Whiting, J. W. M., and B. Whiting. 1975. Behavior of Children in Six Cultures. Cambridge.

Wohwill, J. F., and W. van Vliet. 1985. Habitats for Children: The Impacts of Density. Hillsdale.

Wolfe, M. 1978. Childhood and Privacy. Children and the Environment, eds. I. Altman and J. F. Wohlwill, pp. 175-222. New York. 